\title{
LABORATORY DEVICE FOR CHECKING THE FUNCTIONALITY OF THE ELEVATOR ROPE SENSORS
}

\author{
Leopold HRABOVSKY \\ VSB-Technical University of Ostrava \\ David BOROVSKY \\ Divize Důlní Hydraulika, HENNLICH s.r.o.
}

\begin{abstract}
:
The paper describes the structural design of a laboratory device that allows for presenting operation, simulating work procedures and checking functionality of the elevator "rope sensors" when equalizing different tensile forces in partial ropes of a rope system of traction elevators. The laboratory device is modified for checking operations of commonly used rope sensors. In an overwhelming number of cases, elevator technicians use them for setting up the unequally distributed tensile forces in elevator ropes. The device is equipped with three, mutually attached pulleys, over which the rope is installed. The unknown tensile force in the rope is determined by an "indirect method", i.e. from the resultant of the forces of the rope bent over the pulleys, which have an effect on the force sensor. The tensile force along the rope axis can be determined numerically, but also experimentally, from the inclination angle of the rope installed on the pulleys, diameter of the pulleys, diameter of the rope and the force detected by the force sensor of the stretched rope. The paper presents experimentally obtained tensile force values at the rope sensor, deduced from stretching the rope. The paper also describes the procedure for determining the measured load in the rope by rope sensors of the SWR, SWK and RMT-1 types based on the variable axial force in the rope.
\end{abstract}

Key words: rope equalizer, sensor, steel rope, tensile force, traction lift

\section{INTRODUCTION}

Elevators used in high rise and highspeed applications are particularly sensitive to uneven rope tensions [24], suffering from unnecessary wear, excessive vibrations, and unwelcome noise as a result [9].

In most static systems, the balance must be checked by an installer who manually evaluates the ropes. Unfortunately, these checks are not necessarily based on skill or training, making the process guesswork rather than a science.

The increasing importance of precise tensioning in elevators has created significant demand for better diagnostics $[26,27,28,30]$.

To that end, manufacturers have developed a wide variety of measurement solutions [34], as well as dynamic equalizing tools to respond to balance struggles in real time [25].

There are two basic principles of devices, by the means of which one can set (i.e. "equalize") tensile forces in individual ropes of traction elevator rope systems [29, 31, 32, 33]. Both systems can be characterized by the same advantage, which consists of the possibility to detect tensile forces by a nondestructive method. It means that the tensile force along the longitudinal axis of the rope can be determined without the need to break the rope length.

\section{LITERATURE REVIEW}

One of the device variant $[2,3,4,5,7,9]$ is, at the moment the tensile force in the rope needs to be recorded, placed in a space where the rope is attached using suspension bolt $[2,3]$ to console [6], built-in in the elevator shaft of the given traction elevator or attached to the frame of the given elevator cage $[9,16,18,22]$.

One of the several $[3,10,17]$ structural designs of the hydraulic rope equalizers is presented in [9]. The structural design of the mechanical rope equalizer, which uses a foil tensiometer for detecting the tensile force, is presented in $[2,7]$. The operation and principle of the equalizing tensile forces using a mechanical rope equalizer that utilizes a tensile force sensor are described in [6, 35].

The other variant of the mechanical rope equalizer is based on the principle of bending a girder, propped on two supports $[1,6,21]$. In the technical world, these rope force equalizers are known under the name of "elevator 
rope sensors". A rope sensor [11, 13, 36] is essentially a girder made of steel or casted from an aluminum alloy. Two pulleys [14] with a predefined span are installed on the pegs against the sensor in a revolving way. The third pulley, with its vertical axis being equally far from the other two pulleys, is sliding in the vertical plane that is perpendicular to the horizontal plane that passes through the pulley centers [37].

Paper [6] described some of the deficiencies of the rope sensors. The paper also deduced the relation between the applied force $F[\mathrm{~N}]$ and its impacts on the sensor. Force $F$ $[\mathrm{N}]$, applied to the sensor, depends on the axial force $T[\mathrm{~N}]$ in the rope and on the mutual distance of the pulley centers along both axes of the horizontal plane.

\section{METHODOLOGY OF RESEARCH}

For the purpose of verifying the measured values of the applied tensile forces in the loadbearing rope $T$ [N] [6] using rope tension sensors [11, 14, 19], a measuring device, see Fig. 4 (structural proposal in AutoCAD 2010) and Fig. 3 (3D model in SolidWorks 2012x64 SP 5.0), was proposed and assembled (Fig. 7). This measuring device allows for detecting tensile forces in the ropes utilizing two independent procedures.

In the horizontal plane, the distances of the axes of the pulley centers, over which the rope is placed, are $x[\mathrm{~m}]$ and y [m], Fig. 1a.

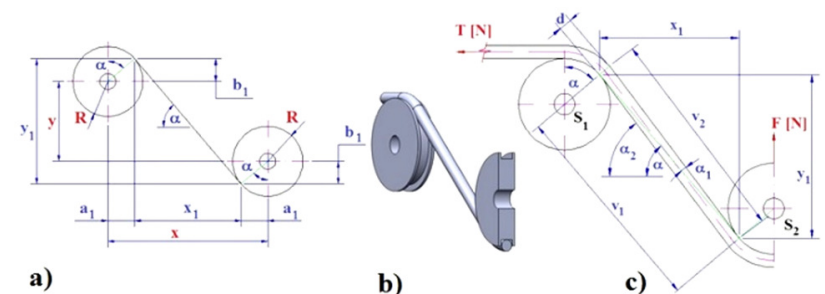

Fig. 1 Rope installed on the pulleys of a rope sensor, i.e. a rope equalizer

\section{Governing equations}

Based on Fig. 1a, (1) through (4) are valid, provided $R=D / 2[\mathrm{~m}]$ is the span radius of the semicircular groove of the rope pulley.

$$
\begin{gathered}
a_{1}=\mathrm{R} \cdot \sin \alpha[\mathrm{m}], \mathrm{b}_{1}=\mathrm{R} \cdot \cos \alpha[\mathrm{m}] \\
x_{1}=\mathrm{x}-2 \cdot a_{1}=\mathrm{x}-2 \cdot R \cdot \sin \alpha[\mathrm{m}] \\
y_{1}=\mathrm{y}+2 \cdot b_{1}=\mathrm{y}+2 \cdot R \cdot \cos \alpha[\mathrm{m}] \\
\alpha=\operatorname{arctg} \frac{y_{1}}{x_{1}}[\mathrm{deg}]
\end{gathered}
$$

Line segment length $v_{1}[\mathrm{~m}]$ (which is, pursuant to Fig. 1c, tangent to the circles) can be expressed by formula (5) and angle $\alpha_{1}$ [deg] pursuant to formula (6), when $d$ [m] is the rope diameter.

$$
\begin{aligned}
& v_{1}=\sqrt{x_{1}^{2}+\mathrm{y}_{1}^{2}}[\mathrm{~m}] \\
& \alpha_{1}=\operatorname{arctg} \frac{d}{v_{1}}[\mathrm{deg}]
\end{aligned}
$$

Angle $\alpha_{2}$ [deg] between the rope longitudinal axis with the horizontal plane (see Fig. 1c) can be determined from formula (7).

$$
\alpha_{2}=\alpha+\alpha_{1}=\operatorname{arctg} \frac{y_{1}}{x_{1}}+\operatorname{arctg} \frac{d}{v_{1}}[\operatorname{deg}]
$$

Fig. 2 shows theoretical values (pursuant to (8) of force $F_{(\alpha 2)}[\mathrm{N}]$ [6] based on changes of angle $\alpha_{2}=0-55^{\circ}$ for the unit value of tensile force $T$ [N] (i.e. $T=1 \mathrm{~N}$ ), see Table 1 , in the rope.

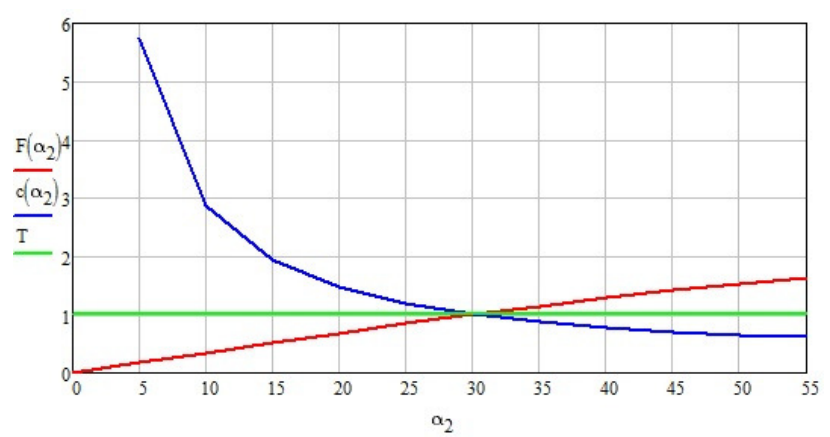

Fig. 2 Force $F_{\left(\alpha_{2}\right)}$ and constant $c_{\left(\alpha_{2}\right)}$ for angle $\alpha_{2}$ and unit value of tensile force $T$

It is clear from Fig. 2 that force $F_{(\alpha 2)}=T[\mathrm{~N}]$ when angle

\begin{tabular}{|c|c|c|c|c|c|c|c|c|c|c|c|}
\hline $\begin{array}{c}\alpha_{2} \\
{[\mathrm{deg}]}\end{array}$ & $0 \quad 5$ & 10 & 15 & 20 & 25 & 30 & 35 & 40 & 45 & 50 & 55 \\
\hline $\begin{array}{c}F_{\left(\alpha_{2}\right)} \\
{[\mathrm{N}]}\end{array}$ & 00.17 & 0.35 & 0.52 & 0.68 & 0.85 & 1.00 & 1.15 & 1.29 & 1.41 & 1.53 & 1.64 \\
\hline $\begin{array}{c}c_{\left(\alpha_{2}\right)} \\
{[-]}\end{array}$ & -5.88 & 2.86 & 1.92 & 1.47 & 1.18 & 1 & 0.87 & 0.78 & 0.71 & 0.65 & 0.61 \\
\hline
\end{tabular}
$\alpha_{2}=\pi / 6=30^{\circ}$. For $\alpha_{2}<30^{\circ}, F_{(\alpha 2)}<T$, and for $\alpha_{2}>30^{\circ}$, $F(\alpha 2)>T$.

Table 1

Relation between the measured force $F_{(02)}$, and constant $c_{(02)}$ and angle $\alpha_{2}$ (rope inclination)

$\begin{array}{lllllllllllll}\alpha_{2} & 0 & 0.09 & 0.17 & 0.26 & 0.35 & 0.44 & 0.52 & 0.61 & 0.70 & 0.79 & 0.87 & 0.96\end{array}$

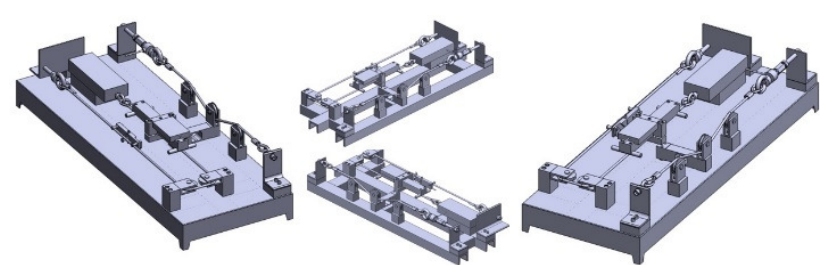

Fig. 3 3D model of the measuring device, created in the SolidWorks 2012x64 SP 5.0 environment

\section{RESULTS}

The first option for detecting the tensile force in the rope using the measuring device (Fig. 7) uses two tensiometric force sensors $\underline{3}$ [15] and $\underline{4}$ [12] (Fig. 4).

The ends of the cable conductors of both sensors $\underline{3}, \underline{4}$ are soldered to the connectors of the "D Sub" connector plug. The connector plugs are plugged into two of the four outlets in the measuring system DS-NET $[13,20]$ DEWESoft. A network cable (with an "RJ45" connector on its both ends) is used for connecting the DEWESoft DS-NET measuring set with a PC. Applied forces $F[N]$ and $T[N]$ (detected by force sensors $\underline{3}$ a $\underline{4}$ ) were displayed in the DEWESoft $X 2$ SP5 software environment, installed on the PC, see Table 2 (Fig. 5, 6). 


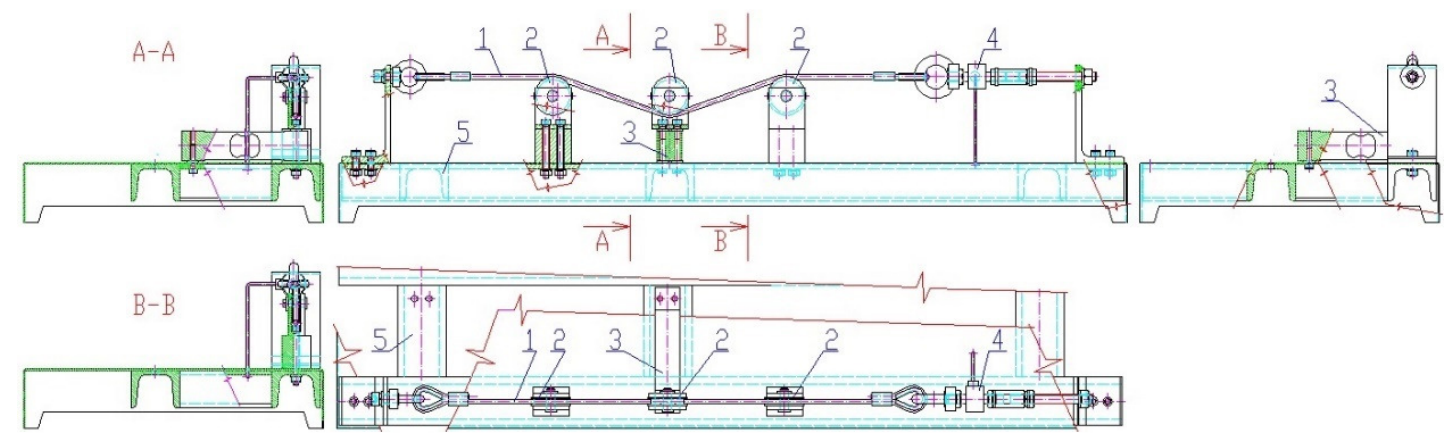

Fig. $42 D$ structural proposal of the $1^{\text {st }}$ variant of the measuring device

Table 2

Forces $T$ and $F$ detected by force sensors $\underline{3}$ and $\underline{4}$ pursuant to the $1^{\text {st }}$ variant on the measuring device

\begin{tabular}{ccccccccccc}
\hline $\mathrm{i}$ & 1 & 2 & 3 & 4 & 5 & 6 & 7 & 8 & 9 \\
\hline$T[\mathrm{~N}]$ & $\mathrm{j}$ & $\mathbf{1 0 0}$ & $\mathbf{1 5 0}$ & $\mathbf{2 0 0}$ & $\mathbf{2 5 0}$ & $\mathbf{3 0 0}$ & $\mathbf{3 5 0}$ & $\mathbf{4 0 0}$ & $\mathbf{4 5 0}$ & $\mathbf{5 0 0}$ \\
$F[\mathrm{~N}]$ & & $\mathbf{6 6 . 6 0}$ & $\mathbf{9 9 . 9 1}$ & $\mathbf{1 3 3 . 2 1}$ & $\mathbf{1 6 6 . 5 1}$ & $\mathbf{1 9 9 . 8 1}$ & $\mathbf{2 3 3 . 1 1}$ & $\mathbf{2 6 6 . 4 1}$ & $\mathbf{2 9 9 . 7 2}$ & $\mathbf{3 3 3 . 0 2}$ \\
& $1^{1}$ & 70.09 & 103.36 & 136.86 & 169.67 & 202.44 & 236.19 & 265.87 & $\mathbf{2 9 5 . 8 2}$ & $\mathbf{3 2 9 . 3 3}$ \\
& $2^{2}$ & 69.86 & 104.24 & 141.62 & 176.25 & $\mathbf{2 0 6 . 4 9}$ & 244.59 & 278.47 & 307.82 & 335.26 \\
$F_{\mathrm{i}, \mathrm{j}}[\mathrm{N}]$ & 3 & 68.23 & 103.51 & 139.14 & 173.76 & 205.85 & 241.34 & 269.19 & 302.86 & 334.15 \\
& 4 & 69.11 & 102.97 & 138.75 & 170.66 & 202.67 & 238,78 & 274.42 & 297.17 & 329.94 \\
& 5 & 68.78 & 103.16 & 140.92 & 173.58 & 203.92 & 239.96 & 264.95 & 298.34 & 330.05 \\
& & $\mathbf{6 9 . 0 1}$ & $\mathbf{1 0 3 . 4 5}$ & $\mathbf{1 3 9 . 4 6}$ & $\mathbf{1 7 2 . 7 8}$ & $\mathbf{2 0 4 . 2 7}$ & $\mathbf{2 4 0 . 1 7}$ & $\mathbf{2 7 0 . 5 8}$ & $\mathbf{3 0 1 . 0 0}$ & $\mathbf{3 3 1 . 7 5}$ \\
$F_{\mathrm{iv}}[\mathrm{N}]$ & & \pm 1.25 & \pm 0.67 & \pm 2.34 & \pm 3.28 & \pm 2.28 & \pm 3.87 & \pm 7.16 & \pm 5.44 & \pm 3.41 \\
$F_{\mathrm{i}} \cdot \mathrm{C}_{(\alpha 2)}[\mathrm{N}]$ & & $\mathbf{1 0 3 . 6 2}$ & $\mathbf{1 5 5 . 3 1}$ & $\mathbf{2 0 9 . 3 8}$ & $\mathbf{2 5 9 . 4 1}$ & $\mathbf{3 0 6 . 7 0}$ & $\mathbf{3 6 0 . 6 0}$ & $\mathbf{4 0 6 . 2 6}$ & $\mathbf{4 5 1 . 9 2}$ & $\mathbf{4 9 8 . 0 9}$ \\
\hline
\end{tabular}

${ }^{1}$ see Fig. $5{ }^{2}$ see Fig. 6

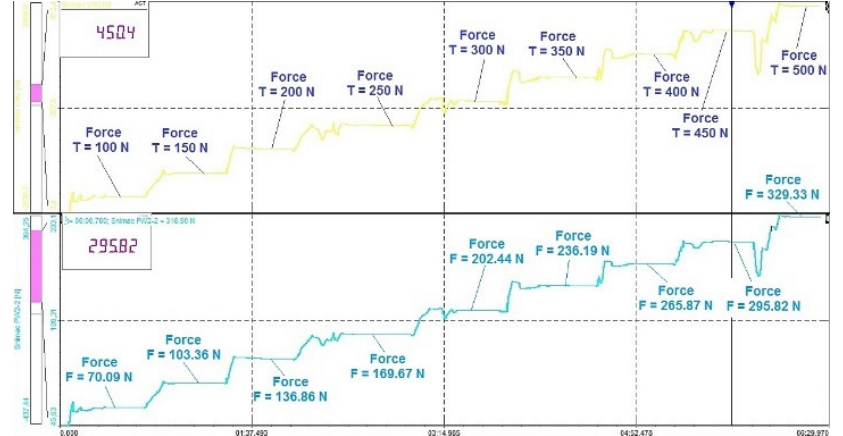

Fig. 5 Records of the monitored forces $T$ [N] and $F[N]$ in the environment of the DEWESoft X2 SP5 software during the experimental test on the measuring device

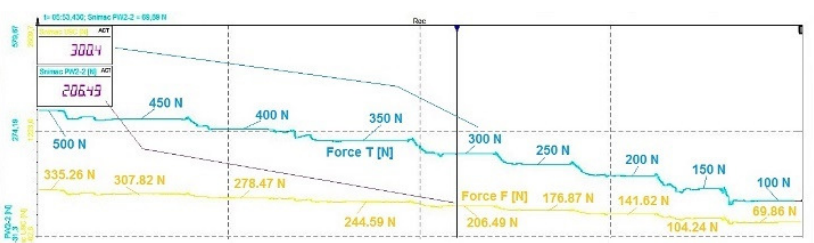

Fig. 6 Records of the monitored forces $T$ and $F$ by force sensors 3 and 4 in the environment of the DEWESoft X2 SP5 software

A standardized eye is formed at each end of the rope 1 $[20,21,23]$. The eye is pressed using an aluminum socket. Using a plastic nut, tensile force $T[\mathrm{~N}]$ along the longitudinal axis of rope $\underline{1}$ is being increased. The immediate value of tensile force $T[\mathrm{~N}]$ is monitored by force sensor $\underline{4}$. The rope is installed (Fig. 4) over three pulleys $\underline{2}$ (inner $\phi=35$ $\mathrm{mm}$ ); the middle pulley is attached by bolts to force sensor $\underline{3}$. Tensile force $\mathrm{T}[\mathrm{N}]$ in rope $\underline{1}$ is created by stretching rope $\underline{1}(\phi \mathrm{d}=5 \mathrm{~mm}$ ). This force (for $x=120 \mathrm{~mm}, y=0 \mathrm{~mm}$ and $\alpha_{2}=19.45^{\circ}$ ) generates force $F[\mathrm{~N}](8)$ applied to sensor $\underline{3}$.

$$
\mathrm{F}=2 \cdot T \cdot \sin \alpha_{2}[N]
$$

All ropes of the same construction must be used for the lift. Steel ropes 6-strand structure are less flexible and have been used in older types of elevators with machines with large diameter pulleys. With modern elevators, the drive components are constantly shrinking. This also reduces the diameter of the pulleys and increases the demand for greater flexibility of the rope, which is an 8-strand structure, wound in a parallel manner. The layer consists of strands with larger and smaller diameter wires, such as Seal, Filler and Warrington.

The second row of Table 2 includes the values of force $F[N]$, calculated pursuant to formula (8). The second through fifth rows of Table 2 shows the values of force $F_{i, j}[N]$, which were measured by force sensor $\underline{3}$ on the measuring device (Fig. 7) upon a change of tensile force $T[\mathrm{~N}]$ in the rope.

The last row of Table 2 shows the value of measured force $F_{\mathrm{i}}[\mathrm{N}]$ multiplied by constant $c_{(\alpha 2)}[-]$. Constant $c_{(\alpha 2)}[-]$ can be expressed as a ratio of the two forces $\left(T\right.$ a $\left.F_{i}[N]\right)$ measured on the measuring device (Fig. 7).

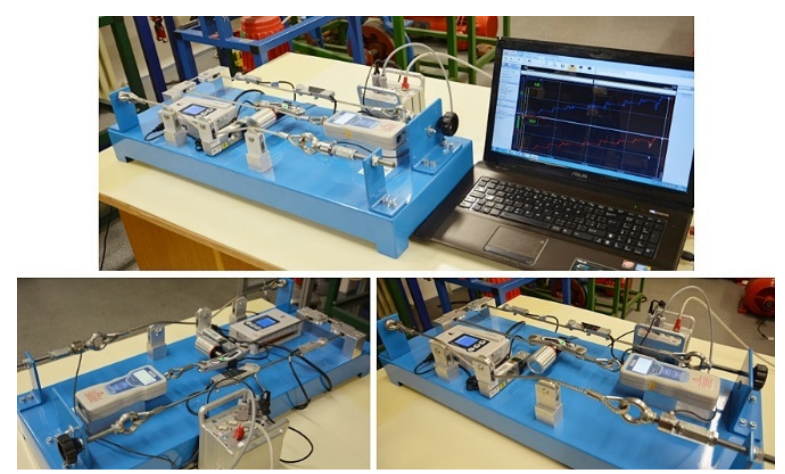

Fig. 7 Laboratory device for checking the functionality of the elevator rope sensors 
By adjusting formula (8), constant $c(\alpha 2)[-]$ can be subsequently determined (9).

$$
c_{(\alpha 2)}=\frac{T}{F_{i}}=\frac{1}{2 \cdot \sin \alpha_{2}}[-]
$$

Force $F_{i, j}[N]$ measured by force sensor $\underline{3}$, multiplied by constant $c_{(\alpha 2)}[-]$ determines the actual value of tensile force $T[\mathrm{~N}]$ in rope $\underline{1}$. Should the measured force $F_{\mathrm{i}, \mathrm{j}}[\mathrm{N}]$ not be multiplied by constant $c_{(\alpha 2)}[-]$, then, for:

a) $\alpha_{2}<\pi / 6\left(=30^{\circ}\right)$, its value would be smaller than $T[\mathrm{~N}]$ $\left(F_{i, j}<T\right)$,

b) $\alpha_{2}=\pi / 6$, its value would be equal to $T[\mathrm{~N}]\left(F_{i, j}=T\right)$,

c) $\alpha_{2}>\pi / 6$, its value would be higher than $T[N]\left(F_{i, j}>T\right)$. The arithmetic mean $F_{i}[N]$ of measured values of holding forces $F_{\mathrm{i}, \mathrm{j}}[\mathrm{N}]$ was calculated with the help of relation (10) and using relation (11), the deviations $\Delta_{\mathrm{i}, \mathrm{j}}[\mathrm{N}]$ of measured values $F_{i, j}[N]$ from the arithmetic mean $F_{i}[N]$ was obtained.

$$
\begin{aligned}
F_{i} & =\frac{\sum_{\mathrm{j}=1}^{n} F_{\mathrm{i}, \mathrm{j}}}{n}[N] \\
\Delta_{\mathrm{i}, \mathrm{j}} & =\mathrm{F}_{i}-\mathrm{F}_{\mathrm{i}, \mathrm{j}}[N]
\end{aligned}
$$

The sample standard deviation $s_{\mathrm{vi}}[\mathrm{N}]$ of the arithmetic mean $F_{i}[N]$ was calculated using relationship $(12)[8,21]$, and the standard deviation $s_{0 i}[\mathrm{~N}]$ of the arithmetic mean $F_{\mathrm{i}}[\mathrm{N}]$ by relation (13) [8].

$$
\begin{gathered}
S_{\mathrm{vi}}=\sqrt{\frac{\sum_{\mathrm{j}=1}^{n} \Delta_{\mathrm{i}, \mathrm{j}}^{2}}{\mathrm{n}-1}}[N] \\
S_{\mathrm{oi}}=\frac{S_{\mathrm{vi}}}{\sqrt{n}}=\sqrt{\frac{\sum_{\mathrm{j}=1}^{n} \Delta_{\mathrm{i}, \mathrm{j}}^{2}}{n \cdot(\mathrm{n}-1)}}[N]
\end{gathered}
$$

In the Table [8] of critical values of Student's distribution, the chosen risk was set to be $5 \%$, and therefore $t_{\mathrm{a}, \mathrm{n}}[-]$, for the number of measurements " $n=5$ " and the risk $a=5 \%$ the Student's coefficient is $t_{5 \%, 5}=2.78$.

The error margin $k_{i}[\mathrm{~N}]$ was calculated by relationship (14).

$$
k_{i}=\mathrm{t}_{5 \%, 5} \cdot s_{\mathrm{oi}}[N]
$$

The last row of Table 3 contains the results of the measured holding force values $F_{\text {iv }}[N]$, given by relation (15).

$$
F_{\text {iv }}=\mathrm{F}_{i} \pm \mathrm{k}_{i}[N]
$$

Table 3

Measured values of force $F_{1, j}$, deviances of the measured $\Delta_{1, j}$

\begin{tabular}{ccccc}
\hline $\mathrm{j}$ & $F_{1, \mathrm{j}}[\mathrm{N}]$ & $\Delta_{1, \mathrm{j}}[\mathrm{N}](11)$ & $\mid \Delta_{1, j}[\mathrm{~N}]$ & $\Delta_{1, j}{ }^{2}\left[\mathrm{~N}^{2}\right]$ \\
\hline 1 & 70.09 & 1.08 & 1.08 & 1.16 \\
2 & 69.86 & 0.85 & 0.85 & 0.72 \\
3 & 68.23 & -0.78 & 0.78 & 0.61 \\
4 & 69.11 & 0.10 & 0.10 & 0.01 \\
5 & 67.78 & -1.23 & 1.23 & 1.52 \\
$\Sigma F_{1, j}[\mathrm{~N}]$ & $\mathbf{3 4 5 . 0 7}$ & & $\Sigma \Delta_{1, j}{ }^{2}[\mathrm{~N}]$ & $\mathbf{4 . 0 2}$ \\
$F_{1}[\mathrm{~N}](10)$ & $\mathbf{6 9 . 0 1}$ & & & \\
\hline
\end{tabular}

The measuring station has been also modified (second variant of the tensile force detection in the rope on the measuring device) for simulating the operation for equalizing tensile forces in the ropes utilizing industrially made rope sensors. Fig. 7 shows rope sensors RMT-1, SWK and SWR installed on the rope of the measuring station [14].

\section{DISCUSSION}

For the purpose of verifying the measured values of the applied tensile forces in the loadbearing rope $T[\mathrm{~N}][6]$ using rope tension sensors $[11,14]$ was proposed and assembled (Fig. 3). This measuring device allows for detecting tensile forces in the ropes utilizing two independent procedures.

The first option for detecting the tensile force in the rope using the measuring device uses two tensiometric force sensors $\underline{3}$ and $\underline{4}$.

In the case of experimental measurements at a laboratory station, the value of the created axial force $T[N]$ in the rope can be monitored on the display of the digital dynamometer. Changes of the generated axial force $T[N]$ over time can be saved in the computer memory and the graphic representation (of axial force $T[N]$ ) can be displayed on the PC monitor in the environment of the software supplied by the manufacturer of the digital dynamometer, i.e. Force Logger version 1.01.

When we know the value of axial force $T[\mathrm{~N}]$, and when we install one of the RMT-1, SWR or SWK rope sensors on the rope, tensile force $T[\mathrm{~N}]$ is created in the loadbearing rope (by tightening the manual plastic nut). This tensile force is monitored by partial sensors as tensile load $T_{G}$ [kg]. Its value can be read on the display of the OMEGA 806 control unit [14].

Rope elevators, also referred to as traction elevators, have a cabin suspended from a system of ropes. Lifting or lowering of the car, run between the guides, is ensured by the frictional force of the steel ropes in the grooves of the traction disk of the elevator machinery. As the load-bearing capacity of the elevator increases, the required number of load-bearing ropes also increases, especially in the case where small diameter ropes are used in traction elevators. The actual weight of the car and the weight of the load must be evenly distributed amongst all supporting ropes that are used in the given layout of the elevator. Currently, several principles are known by which it is possible to detect and also change the values of the instantaneous magnitudes of the tensile forces acting in a system of ropes.

The collaboration of lift company (Liftcomp a.s.) s with authors of this paper a technical problem was chosen, which was to ensure uniform tension in the elevator ropes at various operating conditions. Using the design methods, three ways of solving the uniform tension in elevator ropes were specified. An important result of the cooperation was granted Czech patent No. 306797 named "A tension equalizer in lift carrying rope" (see www.upv.cz). Currently, the patent granted is offered to lift companies for use under licenses.

The presented solution has a practical application $[2,3,5$, 6 , 7]. Authors of Czech patent No. 306797 built four design prototypes, the functionality of which was presented to companies that deal with the installation and servicing of elevators. The practical usability was thus verified, and the functionality approved. 


\section{CONCLUSION}

The paper presents and describes one of the additional technical devices that is used for equalizing initially different tensile forces in the loadbearing ropes of individual elevators.

The technical device called a "rope sensor" is a girder that is attached to the rope using its supports (two pegs). A fixed or sliding peg is located in the center between the rope sensor girder supports.

The system of ropes consists of at least two load-bearing steel ropes with six strands or, from the point of view of easier bending, and currently more widespread, ropes with eight strands.

Rope elevators, also referred to as traction elevators, have a cabin suspended from a system of ropes. The system of ropes consists of at least two load-bearing steel ropes with six strands or, from the point of view of easier bending, and currently more widespread, ropes with eight strands. Lifting or lowering of the car, run between the guides, is ensured by the frictional force of the steel ropes in the grooves of the traction disk of the elevator machinery. As the load-bearing capacity of the elevator increases, the required number of load-bearing ropes also increases, especially in the case where small diameter ropes are used in traction elevators. The construction of the rope does not affect the result of the experiment, because the rope is attached to the steel rope clamps by means of eye rope screw. It is installed on the screw of the rope suspension, see Fig. 4 or Fig. 7.

The rope, in which the tensile force is supposed to be determined, is threaded through the three pegs, of the rope sensor girder. The increasing tensile force in the rope struggles to straighten the twice-bent longitudinal axis of the rope into a straight line. The force that struggles to straighten the bent rope is applied perpendicularly to the rope axis. The force is directly proportional to the tensile force in the rope.

In the paper, we determined the angle, under which the rope longitudinal axis is inclined when the rope passes through three pegs of the rope sensor. The horizontal as well as vertical distances of the center axes of all three pegs have a fundamental impact on the resultant of the measured force. For an angle of the rope inclination smaller than $30^{\circ}$, the value of the measured force is smaller than the real value of the tensile force in the rope. For an angle of the rope inclination bigger than $30^{\circ}$, the value of the measured force is bigger than the tensile force in the rope.

In the paper, we present a structural proposal, 3D model and an implemented laboratory device for checking the functionality of the elevator rope sensors, which was assembled in the Research and testing laboratory for the purpose of verifying equalized forces in the elevator ropes by rope sensors with an accuracy of the equalized forces in the elevator ropes, while using mechanical or hydraulic tensile force equalizers.

\section{ACKNOWLEDGEMENTS}

This work has been supported by The Ministry of Education, Youth and Sports of the Czech Republic from the Specific Research Project SP2020/90.

\section{REFERENCES}

[1] K. Dong-Bok and K. Gab-Soon. "Study on the Development of an Elevator Rope Tension Automatic Equalizer." Journal of the Korean Society of Manufacturing Process Engineers, vol. 19, no. 5, pp. 60-66, 2020.

[2] L. Hrabovsky. "Apparatus Producing an Even Distribution of Strain into Carries." in IOP Conference Series: Materials Science and Engineering, 2017, pp. 1-6.

[3] L. Hrabovsky. "Tensile forces in lift carrier ropes exerted by the fluid pressure." Advances in Science and Technology Research Journal, vol. 13, pp. 31-37, Jul 2019.

[4] J. Kulka, M. Mantic, G. Fedorko and V. Molnar. "Failure analysis of increased rail wear of 200 tons foundry crane track." Engineering Failure Analysis, vol. 67, pp. 1-14, Sep 2016.

[5] L. Hrabovsky and P. Koscak. "Detection and Change of Tension Forces Operating on Elevator Hoist Ropes." in IOP Conference Series: Materials Science and Engineering, 2019, pp. 1-8.

[6] L. Hrabovsky and M. Maslaric "Device designed for detection and setting the required tensile force in ropes." Advances in Science and Technology Research Journal, vol. 12, pp. 200-206, Mar 2018.

[7] L. Hrabovsky and P. Michalik. "A tension equalizer in lift carrying ropes." Advances in Science and Technology Research Journal, vol. 11, pp. 326-332, Dec 2017.

[8] V. Madr, J. Knejzlik, J. Kopecny and I. Novotny. Fyzikální měřeni [Physical measurements. (In Czech)], SNTL Praha, 1991, pp. 304-38.

[9] 3 Cost-Saving Advantages of Hydraulic Rope Equalizers. Internet: https://www.renown-electric.com/blog/3-costsaving-advantages-of-hydraulic-rope-equalizers/ Aug 14, 2018 [Apr. 14, 2020].

[10] Hydraulic traction leveler. Internet: https://www.se-

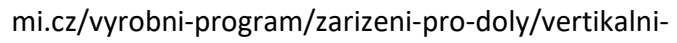
doprava/hydraulicke-vyrovnavace-tahu/ (In Czech) Jul 24, 2015 [May 20, 2020].

[11] Load Weighing Devices. Internet: www.dinacell.com/catalogos/D1262-02-EN.pdf Dec 20, 2019 [May 11, 2020].

[12] PW2C Single point load cells. Internet: www.hbm.cz/wpcontent/uploads/B01990.pdf [Jun 01, 2020].

[13] Sensores-de-medida. Internet: www.sensores-de-medida.es/uploads/ds-net-equipo_de_adquisicion_por_ethernet.pdf Mar 9, 2012 [Jun 08, 2020].

[14] Snímače vážení na lana. Internet: http://www.liftecgroup.com/lana.html (In Czech) Feb 12, 2017 [Jun 11, 2020].

[15] U9C Force Transducer. Internet: www.hbm.cz/wp-content/uploads/B03812.pdf Jul 8, 2020 [Jun 10, 2020].

[16] A. Durna, J. Fries, L. Hrabovsky, A. Sliva and J. Zarnovsky. "Research and development of laser engraving and material cutting machine from 3D printer." Management Systems in Production Engineering, vol. 28, pp. 47-52, Jan 2020.

[17] J. Kulka, M. Mantic, M. Kopas, E. Faltinova and L. Hrabovsky. "Simulation expertise analysis of ropes in the horizontal belaying system." Scientific Journal of Silesian University of Technology - Series Transport, vol. 103, pp. 53-67, Jun 2020. 
[18] P. Michalik, J. Dobransky, L. Hrabovsky and M. Petrus, M. "Assessment of the manufacturing possibility of thinwalled robotic portals for conveyance workplaces." Advances in Science and Technology Research Journal, vol. 12, no. 1, pp. 338-345, Mar 2018.

[19] M. Petrus, P. Michalik, L. Straka, L. Hrabovsky, J. Macej, P. Tirpak and J. Jusko. "The evaluation of the production of the shaped part using the workshop programming method on the two-spindle multi-axis CTX alpha 500 lathe." Open Engineering, vol. 9, no. 1, pp. 660-667, Dec 2019.

[20] M. Mantic, J. Kulka, M. Kopas, E. Faltinova and L. Hrabovsky. "Limit states of steel supporting structure for bridge cranes." Scientific Journal of Silesian University of Technology - Series Transport, vol. 108, pp. 141-158, May 2020.

[21] L. Hrabovsky, G. Fedorko, L. Mlynek and P. Michalik. "Electromagnetic locking devices of car handling units." Scientific Journal of Silesian University of Technology - Series Transport, vol. 107, pp. 73-83, May 2020.

[22] G. Fedorko, D. Heinz, V. Molnar and T. Brenner. "Use of mathematical models and computer software for analysis of traffic noise." Open Engineering, vol. 10, pp. 129-139, Mar 2020.

[23] V. Molnar and M. Sabovcik. "Static testing evaluation of pipe conveyor belt for different tensioning forces." Open Engineering, vol. 9, pp. 580-585, Dec 2019.

[24] M. Calvetti, G. Piano Mortari, A. Placci and M. Rijssenbeek. "A computer-aided system for MWPC wire tension control". Nuclear Instruments and Methods, vol. 174, pp. 285289, Aug 1980.

[25] K. Sung-Duck. „Development of Nondestructive Detecting System for Elevator Wire Ropes using Hall-effect Sensors." Journal of Sensor Science and Technology, vol. 10, pp. 3341, Oct 2001.

[26] H.D. Nagel. "Brake Regulating Apparatus for an Elevator Car." U. S. Patent. 548 644, 1997.

[27] T. Tyni and J. Ylinen. "Evolutionary bi-objective optimisation in the elevator car routing problem." European Journal of Operational Research, vol. 169, pp. 960-977, Mar 2006.

\section{Leopold Hrabovský}

ORCID ID: 0000-0003-3700-8041

VSB-Technical University of Ostrava

Faculty of Mechanical Engineering,

Institute of Transport

17. listopadu 2172/15,

70800 Ostrava-Poruba, Czech Republic

e-mail: leopold.hrabovsky@vsb.cz

\section{David Borovský}

Divize Důlní Hydraulika, HENNLICH s.r.o.

Palhanecká 17, 747 07, Opava-Jaktař, Czech Republic

e-mail: borovsky@hennlich.cz
[28] H. Inaba, M. Shigeta, T. Ando, A. Nokita and M. Konya. "Attitude control system of a super-highspeed elevator car based on magnetic guides." in Proceedings of IECON'94 $20^{\text {th }}$ Annual Conference of IEEE Industrial Electronics, 1994, pp. 1028-1033.

[29] G.R. Yos and T.R. Rothenfluh. "Configuring elevator systems." International Journal of Human-Computer Studies, vol. 44, pp. 521-568, Mar 1996.

[30] Y.T. Lee, T. S. Kim, H.S. Cho, D.K. and B.D. Choi. "Performance analysis of an elevator system during up-peak." Mathematical and Computer Modelling, vol. 49, pp. 423431, Feb 2009.

[31] H.M. Ryu, S.J. Kim, S.K. Sul, T.S. Kwon, K.S. Kim, Y.S. Shim and K.R. Kim. "Dynamic load simulator for high-speed elevator system." in Proceedings of the Power Conversion Conference-Osaka 2002, 2002, pp. 885-889.

[32] V.A. Gendon, and E.A. Belotserkovskii. "Method of replacing head ropes on multi rope hoisting machines using an equalizer rope." Shakhtnoe Stroit. (USSR) Journal, vol. 1. pp. 20-21, Oct 1985.

[33] Z.Z.Z.G.L. Guoliang. „Analysis of Fracture Causes of Steelwire Rope Equalizer Tension Rod for CDQ." Laigang Science \& Technology, vol. 4, pp. 30-36, Apr 2002.

[34] L. Hrabovsky, R. Brazda, J. Bobok, T. Mlcak. „Tension compensator in elevator carrying cables." CS PUV2016-31992, Apr 13, 2016.

[35] B. Stehlikova, V. Molnar, G. Fedorko, P. Michalik and A. Paulikova. "Research about influence of the tension forces, asymmetrical tensioning and filling rate of pipe conveyor belt filled with the material on the contact forces of idler rolls in hexagonal idler housing." Measurement, vol. 156, May 2020.

[36] V. Molnar, G. Fedorko, S. Honus, M. Andrejiova, A. Grincova, P. Michalik and J. Palencar. "Research in placement of measuring sensors on hexagonal idler housing with regard to requirements of pipe conveyor failure analysis." Engineering Failure Analysis, vol. 116, Oct 2020.

[37] L. Rudolf, J. Fries and O. Ucen. "Long spindle design for grinding." MM Science Journal, vol. 2020(1), pp. 37653768, Mar 2020. 